\title{
Involvement of Cerebellum in Emotional Behavior
}

\author{
P. STRATA ${ }^{1}$, B. SCELFO $^{1}$, B. SACCHETTI ${ }^{1,2}$ \\ ${ }^{1}$ National Institute Neuroscience-Italy, Turin, Italy, ${ }^{2}$ Department of Neuroscience University \\ of Turin, Turin, Italy
}

Received December 8, 2010

Accepted February 16, 2011

On-line July 19, 2011

\section{Summary}

In the last decade a growing body of data revealed that the cerebellum is involved in the regulation of the affective reactions as well as in forming the association between sensory stimuli and their emotional values. In humans, cerebellar areas around the vermis are activated during mental recall of emotional personal episodes and during learning of a CS-US association. Lesions of the cerebellar vermis may affect retention of a fear memory without altering baseline motor/autonomic responses to the frightening stimuli in both human and animal models. Reversible inactivation of the vermis during the consolidation period impairs retention of fear memory in rodents. Recent findings demonstrate that long-term potentiation (LTP) of synapses in the cerebellar cortex occurs in relation to associative fear learning similar to previously reported data in the hippocampus and amygdala. Plastic changes affect both excitatory and inhibitory synapses. This concomitant potentiation allows the cerebellar cortical network to detect coincident inputs, presumably conveying sensorial stimuli, with better efficacy by keeping the time resolution of the system unchanged. Collectively, these data suggest that the vermis participates in forming new CS-US association and translate an emotional state elaborated elsewhere into autonomic and motor responses.

\section{Key words}

Fear conditioning $\bullet$ Cerebellum $\bullet$ Learning and memory $\bullet$ Purkinje cell $\bullet$ LTP/LTD

\section{Corresponding author}

Piergiorgio Strata, National Institute of Neuroscience-Italy, University of Turin, Corso Raffaello 30, 10125 Turin, Italy. Fax: +39-011-6708174. E-mail: piergiorgio.strata@unito.it

\section{A brief history}

Following a long period of time characterized by very speculative discussions on the functional role of cerebellum, it was only at the beginning of the $19^{\text {th }}$ century that hypothesis were based on scientific experiments. Rolando $(1809,1823)$ performed cerebellar lesion and described impaired motor, but not sensory or intellectual functions. Immediately after the publication of the French translation of the paper by Rolando (1823), Flourens (1824) noticed that 'all movements persist following ablation of the cerebellum: all that is missing is that they are not regular and coordinated'. This concept was supported by a series of experiments performed later. Towards the end of the century Luciani (1891) described the three basic symptoms of cerebellar lesion: asthenia, atonia and astasia while Holmes (1917) provided a detailed picture of human pathology. A complete collection of data on this early phase of cerebellar physiology and pathology can be found in the classical book by Dow and Moruzzi (1958). In the 1960s John Eccles, Masao Ito and Janos Szentágothai and their collaborators (Eccles et al. 1967a) provided a full picture of the cerebellar cortex wiring and identified the excitatory and the inhibitory nature of each cell type.

A new period in the study of the cerebellar function started with a seminal paper by Marr (1969). By theoretical speculation he provided an original theory proposing that the cerebellar cortex has the task of learning motor skills for movement and posture (see below) (Strata 2009). Since then, there has been a flurry of papers testing different mechanisms of learning and memory processes in the cerebellum by using several 
other approaches at molecular, cellular and behavioral level (see Ito 2001).

More recently, several papers addressed the issue of the cerebellar participation to emotional processes. The results have been obtained by means of new cellular technologies, of brain imaging and by studying behaviorally induced changes in the brain (Sacchetti et al. 2005, 2009, Strick et al. 2009, Schmahmann et al. 2009). For a more detailed history on cerebellar functions see Glickstein et al. (2009).

\section{Cerebellum and emotions}

Emotion is an affective state involving a high level of activation of evolutionary adaptive responses that allow people and animals to deal adequately with a broad range of situations with very limited conscious reasoning. A link between cerebellum and emotions could be envisaged already by the experiments performed by Moruzzi in the thirties (Moruzzi 1938, see Dow and Moruzzi 1958). He showed that stimulation of the cerebellar vermis, but not of the hemispheres, interferes with autonomic reactions, by limiting blood pressure oscillations and induced hyperventilation. In addition, the same stimulation affects the 'sham rage' which occurs spontaneously in acute thalamic cats and which is characterized by outbursts of mass activity resembling an infuriated animal. Following vermal stimulation the autonomic responses consisting in increased blood pressure, mydriasis and retraction of the lid were clearly inhibited. Therefore, Moruzzi (1938) suggested that the cerebellum acts on an ensemble of behavioral responses that belong to a complex autonomic reaction. The demonstration of anatomical connections between the fastigial nucleus and the hypothalamus (Snider 1950) suggested that the vermal area of the cerebellum is involved in emotional manifestation (see Sacchetti et al. 2005).

An increasing amount of evidence has confirmed that the cerebellum is indeed involved in emotional behavior and particularly in fear-related processes. Vermal lesions decrease the reactivity of animals to fearful stimuli and attenuate a variety of reactions related to fear such as the freezing response of a rat in the presence of a cat, fear behavior in an open field and neophobic reactions (Snider and Maiti 1976, Bernston and Torello 1982, Supple et al. 1987).

Furthermore the cerebellar cognitive affective syndrome, that occurs when lesions involve the vermis and fastigial nucleus, implies, in adult and children, a dysregulation of affect (Schmahmann and Sherman 1998). A cerebellar role in the modulation of aggression and mood appears in children with the posterior fossa syndrome following surgery involving the vermis, and during clinical and experimental neurosurgical manipulation.

Following the great amount of observations supporting the role of the cerebellum in emotional processes the hypothesis of the "limbic cerebellum" (vermis and fastigial nucleus) as part of the Papez circuit has been formulated (Bernston and Torello 1982).

\section{Learning-related synaptic plasticity in the cerebellum}

The search for neural substrates of learning and memory in model systems has identified a number of sites in the mammalian brain. Long-term potentiation (LTP) has received a great amount of attention in the last 30 years since it was first described by Bliss and Lømo (1973). This interest has been fueled to a large degree by the widely held hypothesis that learning and memory is mediated by changes in the strength of synapses in neural circuits. According to this hypothesis, neural activity during learning gives rise to long-term changes in synaptic strength, which allow memories to be stored and later retrieved.

The large number of parallel fibers that connect to a single Purkinje cell and the one-to-one relationship between a climbing fiber terminal arbor and a single Purkinje cell have suggested to Marr (1969) a simple model of feed-forward neural network which constitutes the basis for a learning machine. The signals conveyed to the cortex by the high number of granule cells through their parallel fibers (in the human cerebellum the number of granule cells is $10^{11}$ ), could be reinforced by a longlasting increase of the synaptic efficacy on the Purkinje cell induced by the concomitant discharge of the climbing fiber. Subsequently Albus (1971) modified Marr's theory proposing that the synchronous activation of these two inputs could lead to a long-term depression (LTD) of the parallel fiber synapses, thus reducing the inhibition on the nuclei. In the early 70's Ito (see Ito 1984) provided experimental evidence in favor of these hypotheses showing the presence of LTD in the parallel fiber synapses following paired stimulation of the parallel and climbing fiber inputs to the Purkinje cell. Later Thompson and Yeo (Thompson 1990, Attwell et al. 
2002) applied this idea to the classic Pavlovian conditioning. As previously mentioned, in the eye blink conditioning an unconditioned stimulus (US), consisting in a puff of air to the cornea, is conveyed to the Purkinje cell via the climbing fibers, whereas the mossy fibers relay the conditioned stimulus (CS), usually a sound. The association of the two stimuli induces an LTD in the parallel fiber synapses, lowers the Purkinje cell activity and, by a mechanism of disinhibition, allows the conditioned signal to be carried to the cerebellar nuclei by the collaterals of the mossy fiber pathway, thus eliciting an eye blink conditioned reflex (Fig. 1).

In the other form of cerebellar motor learning, the VOR, the change of the head angle due to head movement rotation must be compensated by an opposite, but corresponding change in the angle of the eye movement (gain of the VOR). Learning associated with the adaptation of the gain of the VOR to produce more accurate eye movements requires the cerebellar cortex. The mossy fiber input is believed to encode the motor command, and the climbing fiber input encodes error signals from the retina. Memory for this adaptation is thought to be encoded as LTD in the Purkinje cell by coincident stimulation of parallel fiber and climbing fiber inputs (Ito 1984, 2001).

A common feature in both forms of learning is the activation of the climbing fiber which causes a complex spike leading to an increase in the intracellular calcium. IP3-mediated mobilization of $\mathrm{Ca}^{2+}$ from intracellular stores is essential for LTD in cerebellar slices (Miyata et al. 2000). At the same time glutamate binding to AMPA receptors and to mGluR1s causes phospholipase $\mathrm{C} /$ diacylglycerol activation of $\mathrm{PKC}$, which phosphorylates the AMPA receptor GluR2 subunit thus triggering endocytosis of the receptors (Matsuda et al. 1999). The targeted expression of a PKC inhibitory peptide in Purkinje cells blocks both in vitro LTD and VOR adaptation (De Zeeuw et al. 1998, Goossens et al. 2001). Also the presence of intact receptors at the parallel fiber-Purkinje cell synapse like mGluR1 and the GluRdelta2 subunit seems to be essential for LTD induction and motor learning. In mutant mice deficient of either mGluR1 or GluRdelta2 both in vitro LTD and motor performances and learning are disrupted (Conquet et al. 1994, Hirano et al. 1995, Funabiki et al. 1995).

Since then a growing body of data described in detail the molecular cascades and receptors implicated in these forms of plasticity and several studies demonstrated that the same molecules and cascades are also involved in

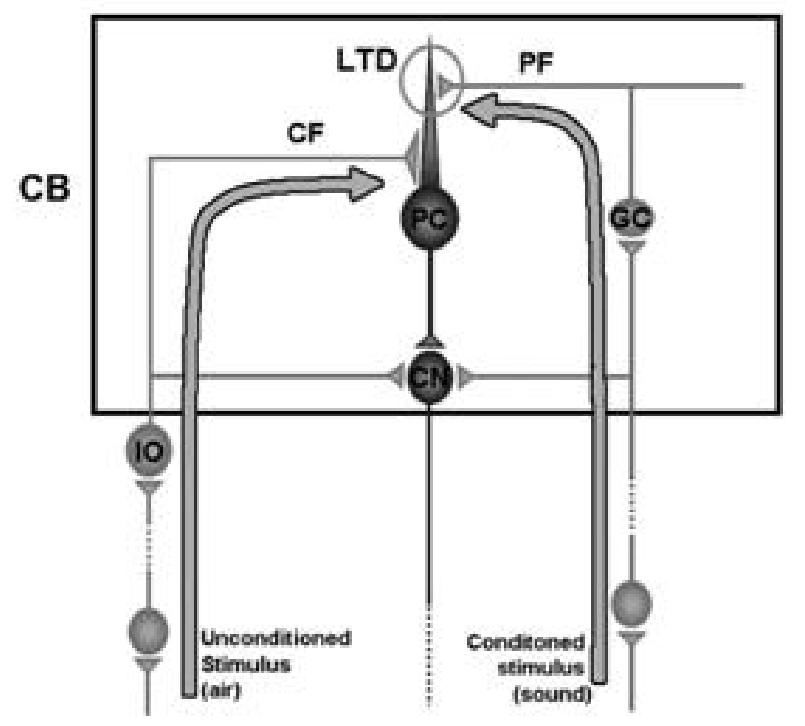

Fig. 1. Cerebellar circuit involved in the eye blink conditioning. In this kind of classical conditioning the US (a puff of air) is carried by the climbing fibers (CFs) originating from the inferior olive (IO) neurons, while the mossy fibers relay the CS (a sound). The association of the two stimuli induces an LTD at the parallel fiber (PF) synapses onto the Purkinje cell (PC). CB: cerebellar cortex, GC: granule cell, $\mathrm{CN}$ : cerebellar nuclei.

the regulation of motor behavior and learning providing a link between cellular processes and behavior.

\section{Recent findings on cerebellar synaptic plasticity related to fear learning}

The use of well-controlled behavioral paradigms, such as classical conditioning, has permitted to relate learning and memory to synaptic plasticity in specific brain areas (Thompson 1986, Schreurs and Alkon 1993). In this context, fear conditioning represents a powerful and very effective tool since fear is a basic evolutionarily conserved emotion related to survival. In this form of associative learning, namely fear conditioning, an animal learns to relate a neutral stimulus (the conditioned stimulus) with a dangerous one (the unconditioned stimulus) (LeDoux 1994).

Considerable progress in mapping the neural circuitry underlying fear conditioning contributed to disclose the synaptic and molecular mechanisms related to the formation and storage of fear memories. In general, the focus of these studies has been to examine the possible relation between fear conditioning and synaptic plasticity in the amygdala and hippocampus and to describe the properties of synaptic plasticity in these brain structures (Maren 2001).

Earlier studies indicate that both hippocampal 
and amygdaloid NMDA receptors are involved in the acquisition of Pavlovian fear conditioning in rats (Fanselow et al. 1994, Maren 1996). Moreover, several studies have directly assessed amygdaloid synaptic transmission during, or shortly after, fear conditioning (Clugnet and LeDoux 1990). These studies suggest that hippocampal LTP is involved in encoding contextual representations whereas amygdaloid LTP is involved in the formation of CS-US associations (Kim and Fanselow 1992, LeDoux 2000).

The involvement of the cerebellum in emotional behavior has raised the question of whether this structure is also a site for plasticity related to learning and memory of emotional processes. A useful technique to investigate this issue is the use of reversible inactivation induced by several drugs like tetrodotoxin (TTX) and lidocaine which block fast voltage gated sodium channels and the use of selective receptors agonists/antagonists. These substances can be administered in specific brain structures at different phases of the memory formation and the role of each structure can be assessed through behavioral tests in these conditions (Ivanova and Bures 1990, Bast et al. 2001).

Brief and reversible inactivation of the cerebellar vermis with TTX administered at different time intervals after the acquisition of associative fear impaired both the contextual and the CS freezing response during the retrieval phase. In each experiment the retrieval was performed long after the effect of the TTX had passed so the observed amnesic effects were due only to disruption of memory consolidation (Sacchetti et al. 2002). These data strongly support the important role of the vermis in the formation of emotional memory.

Recent works have investigated in detail the neural mechanisms of cerebellar involvement in fear learning. Synaptic plasticity in the cerebellar cortex associated with fear learning has been studied in our laboratory (Sacchetti et al. 2004). Excitatory postsynaptic currents evoked in the Purkinje cell following the activation of parallel and climbing fibers were evaluated on cerebellar slices 10 minutes and 24 hours after the acquisition session in conditioned and in two groups of control animals; unpaired animals, which received the CS and US in a temporally uncorrelated manner, and naïve animals, which were left in their home cage. In conditioned animals trained with paired CS and US the parallel fiber-mediated postsynaptic current was significantly larger relative to the other two groups at 10 and 24 hours after the acquisition session (Sacchetti et

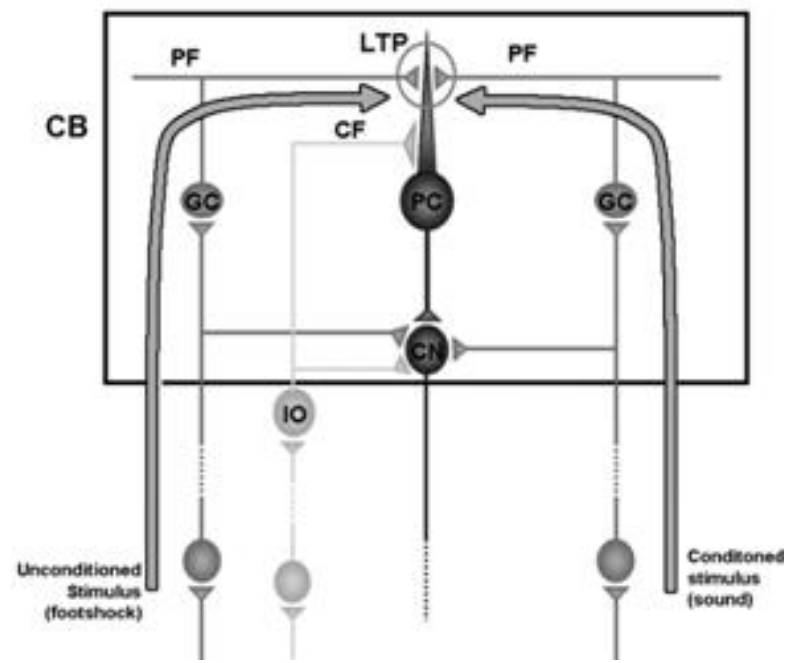

Fig. 2. Hypothetical cerebellar circuit involved in fear conditioning. The two sensorial stimuli constituted by the CS and US are conveyed by two separate parallel fiber (PF) channels. In our hypothesis repetitive and conjunctive activation of the two beams during acquisition of fear responses induces an LTP at the involved parallel fiber synapses. CB: cerebellar cortex, GC: granule cell, IO: inferior olive, CN: cerebellar nuclei, CF: climbing fiber.

al. 2004). These results provide evidence for a behaviorally induced long-term synaptic plasticity in the cerebellar cortex. The synaptic changes that we observed were restricted to vermal lobules $\mathrm{V}$ and VI where acoustic and nociceptive stimuli converge (Snider and Stowell 1944, Saab and Willis 2003). Although this form of plasticity could reflect the facilitation of storage by other mechanisms or at a different location, we suggest that this synaptic change may be part of the neural substrate of fear memory in the cerebellum.

At variance with cerebellar LTD encoding motor memory of the eye blink reflex and VOR, the plastic change that we observed consisted of a long-lasting potentiation of the synapse between parallel fibers and Purkinje cell. This phenomenon was never reported before in the cerebellar cortex in vivo although in vitro experiments have shown that a similar form of postsynaptic LTP is induced in the cerebellar cortex by repetitive activation of the parallel fibers (Lev-Ram et al. 2002). Experiments performed by our group have shown that this in vitro LTP is occluded in cerebellar slices from conditioned animals suggesting that the in vivo potentiation induced by the associative learning shares common features with the latter one (Zhu et al. 2007). Therefore it is possible that the LTP related to fear learning is the result of conjunctive activation of two separate parallel fibers channels conveying CS and US stimuli (Fig. 2). In this respect it has to be underlined that 
parallel fibers are known to carry, together with acoustic inputs, also nociceptive information (Saab and Willis 2003).

The functional characteristics of a neuron are the outcome of a complex interaction between synaptic strength and intrinsic membrane properties. Several evidences indicate that memory processes also involve activity-dependent changes in the intrinsic excitability of neurons (Marder et al. 1996, Thompson et al. 1996, Saar and Barkai 2003, Cudmore and Turrigiano 2004). Laboratory studies have shown that associative learning paradigms, such as the conditioning of the nictitating membrane response, can affect simple spike activity of Purkinje cells from cerebellar lobule VI (Berthier and Moore 1986, Gould and Steinmetz 1996, Thompson 1990) and is related to a significant increase of intrinsic excitability of Purkinje cell dendrites (Schreurs et al. 1997, 1998). This intrinsic plasticity may represent an additional storage mechanism for memory. Therefore we evaluated the Purkinje cell passive and active membrane properties and their possible change in relation to associative fear learning by means of whole cell currentclamp recordings. The experimental conditions were the same as for the study of Sacchetti et al. (2004). Several parameters related to passive and intrinsic excitability properties of the membrane were measured: input resistance, inward rectification, maximal firing frequency, the first inter-spike interval, post-burst afterhyperpolarization and action potential threshold and amplitude. Although the freezing response during the retrieval sessions was present only in the group of conditioned animals none of the evaluated parameters was significantly different between the three studied groups also in those cells where parallel fiber-Purkinje cell synapse was potentiated (Zhu et al. 2006). This result shows that fear learning does not affect the intrinsic membrane properties involved in Purkinje cell firing. Therefore, at the level of Purkinje cell, the plastic change associated with fear conditioning is specifically restricted to synaptic efficacy.

Most studies on learning-related long-term synaptic changes have focused on identifying the mechanisms of synaptic plasticity at excitatory synapses (Levy and Steward 1979, Carew et al. 1981, Schreurs and Alkon 1993). However if one considers the widespread distribution of inhibitory synapses and receptors for inhibitory transmitters, GABA and glycine, throughout the central nervous system it is reasonable to assume that inhibition contributes to learning and memory processes as well as excitation.

The role of inhibitory circuits in the control and expression of fear responses has been recognized and investigated in the last few years. It is already known that fear conditioning involves the induction of LTP of excitatory synaptic transmission in the lateral amygdala, which is tightly controlled by GABAergic inhibition ( $\mathrm{Li}$ et al. 1996, Lang and Parè 1997). Moreover long-term synaptic changes of the inhibitory synapses have been reported to mediate auditory conditioning of goldfish escape behavior (Oda et al. 1998) and impairment in GABAergic transmission due to deletion of the delta subunit of the $\mathrm{GABA}_{\mathrm{A}}$ receptor leads to enhancement of hippocampus-dependent trace fear conditioning (Wiltgen et al. 2005). These evidences strongly point towards a crucial role of the inhibitory network in the establishment of emotional memory.

Cerebellar Purkinje cells exhibit sustained spontaneous inhibitory activity due to the massive GABAergic innervation from basket and stellate cells in the molecular layer and from neighboring Purkinje cells via their collaterals (Eccles et al. 1967b). In spite of the considerable amount of data suggesting a crucial role of inhibition in learning and memory only a few studies so far have been directed to clarify a possible relation between these processes and plastic changes of inhibitory synapses.

Very recently we investigated the possibility that also inhibitory synapses in the cerebellar cortex can be modified in relation to fear learning. Whole-cell patchclamp recordings of spontaneous and miniature GABAergic events onto the Purkinje cell showed that the frequency but not the amplitude of these events is significantly greater up to 24 hours after the conditioning session (Scelfo et al. 2008) implying a presynaptic form of inhibitory LTP.

The fact that fear learning is accompanied by an LTP of both the excitatory and inhibitory inputs to Purkinje cells raised the question of the possible significance of this concomitant potentiation. Neuronal information processing requires specific levels of excitatory and inhibitory signaling. In several brain structures it has been shown that precisely timed signal processing depends on direct monosynaptic excitation and underlying disynaptic inhibition (feed-forward inhibition, FFI) (Pouille and Scanziani 2001, Mittmann et al. 2005, Blitz and Regehr 2005). All theories of timing concerning the cerebellum require that the output of the cerebellar cortex, encoded in the axons of Purkinje cells, 
A

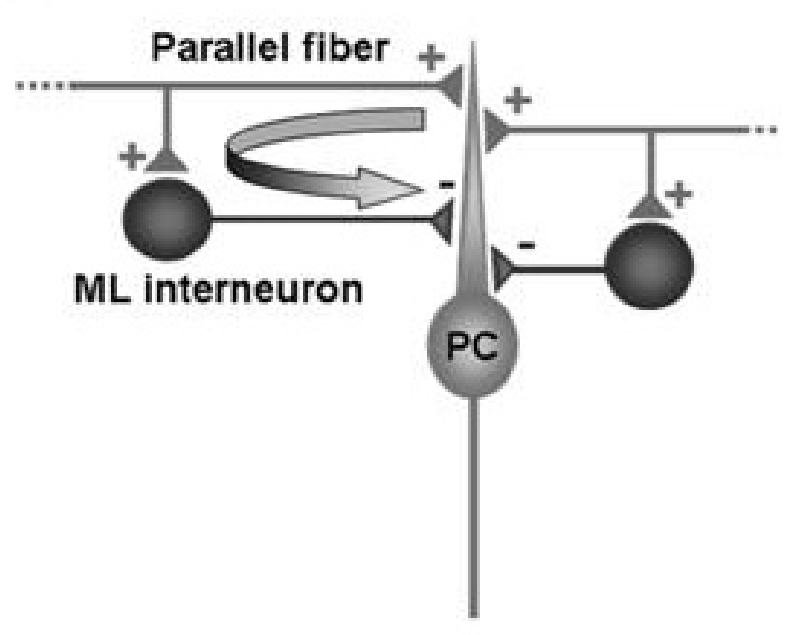

B

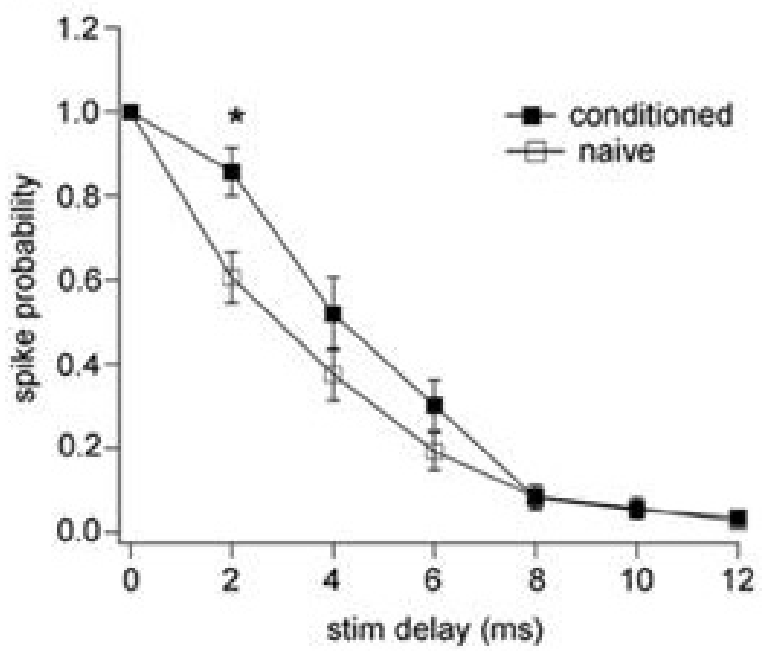

Fig. 3. Effect of the integration of the learning related excitatory and inhibitory LTP in the cerebellar cortex. A) Schematic of the cerebellar circuit of feed-forward inhibition. Activation of a beam of parallel fibers is rapidly followed by synaptic inhibition. A Purkinje cell (PC) may be both directly excited and then inhibited with disynaptic delay via molecular layer (ML) interneurons activated by the same set of active parallel fibers. B) The significance of the simultaneous potentiation of both the inhibitory and excitatory synapses on Purkinje cells was assessed through the probability distribution (mean \pm SEM) of spike generation as a function of parallel fibers stimulation delay. The filled squares represent the spike probability of conditioned animals while empty squares refer to the same probability for naïve animals. $* \mathrm{P}<0.05$. The experiment was performed in artificial cerebrospinal fluid (ACSF) allowing both excitatory and inhibitory synapses to be activated (from Scelfo et al. 2008. Copyright 2008, National Academy of Sciences, USA).

is precisely tuned in response to sensory stimulation. This is achieved through effective integration of correlated activity onto the Purkinje cell, which, to this aim, must be endowed with the ability to act as coincidence detector. A work perfomed in vitro demonstrated that in the cerebellar cortical network the precision of time spiking in Purkinje cells is strongly regulated by GABAergic synapses through FFI (see Fig. 3) and that effective summation for spike generation of multiple asynchronous parallel fiber inputs can occur within a time window of only a few milliseconds (Mittmann et al. 2005).

In the fear conditioning paradigm, we found that both excitatory and inhibitory synapses onto the Purkinje cells are changed after fear learning. Therefore we explored the possibility that fear related long term plastic changes at synaptic level may affect this time window and thus influence the output of the whole neuronal network. Through patch-clamp recordings on coronal slices we evaluated the probability for Purkinje cell spike generation as a function of the delay in the activation of two independent parallel fiber beams. We found that, following fear learning, Purkinje cells are able to integrate excitatory inputs with higher probability within short delays (up to $4 \mathrm{~ms}$, see Fig. 3), but the width of the whole window is unchanged. These results show that excitatory LTP ensures a more effective detection while inhibitory potentiation serves to maintain the coincidence detection unchanged ensuring that the temporal fidelity of the network is maintained (Scelfo et al. 2008).

\section{Concluding remarks}

Our recent findings on cerebellar plasticity related to fear learning strongly support the view that the cerebellum is not only a site associated with emotional behavior and memory, but it is actively involved in these processes.

Further insights into the role of cerebellum in emotion and cognition come from recent in vivo studies in human subjects. Neuroimaging reveals a pattern of cerebellar activation in which pain response and learning activate different cerebellar regions (Ploghaus et al. 1999, 2000, 2003). Painful heat activates the anterior cerebellum around the vermis while a sensory cue that anticipates the painful stimulation leads to activation of posterior cerebellar vermis (Ploghaus et al. 1999, 2000). Therefore, nearby but separate regions are engaged during fear experience and associative learning, i.e. some regions of the human cerebellum are activated by associative processes independent of the direct regulation of motor/autonomic processes. A similar conclusion comes from another study in which fear conditioning 
activated the cerebellum (Fisher et al. 2000).

Damasio et al. (2000) reported a marked activation of midline cerebellum during mental recall of emotional personal episodes. The authors used functional imaging to compare brain regions activated by the recall of a neutral and an emotionally charged personal episode. They concluded that "although the cerebellum was not included in the hypothesis, we believe that the evolutionarily older components of the cerebellum probably are involved in the coordination of emotional responses and in the learned adjustment of those responses in a social setting”. More recently, Singer et al. (2004) used functional imaging to assess brain activity while healthy subjects experienced a painful stimulus and when they observed their loved partner receiving a similar pain stimulus. Among other structures, anterior cerebellum around the vermis was activated in subjects receiving the painful stimulation while posterior cerebellar vermis was activated in the same subjects when observing pain of others. These results suggest that cerebellum is also involved in the empathic experience related to pain.

Imaging studies are correlational in nature, so they cannot establish whether a structure is necessary for emotional learning. The role of the cerebellum is better assessed by study of the effects of cerebellar damage.
Conditioned bradycardia caused by pairing a tone with a painful stimulation is impaired in patients with medial cerebellar lesions (Maschke et al. 2002). Cerebellar stroke does not affect basal autonomic/motor responses to CS and US, in agreement with a similar result obtained in animals with vermal lesions (Supple and Leaton 1990). Similarly, cerebellar stroke does not significantly affect baseline emotional responses in humans (Turner et al. 2006).

In conclusion, while the role of the cerebellum in motor coordination is widely accepted, the notion that it is involved in emotional experience has only recently gained interest. The cerebellum as a site of plasticity implicated in this kind of memories confers to this structure an important role in the complex neural network underlying emotional behavior.

\section{Conflict of Interest}

There is no conflict of interest.

\section{Acknowledgements}

The experiments described in this paper have been supported by grants of the Italian Space Agency, DCMC grant, the Italian Ministry of University and Research, the European Community contract number 512039, Regione Piemonte and Compagnia San Paolo Foundation.

\section{References}

ALBUS JS: A theory of cerebellar function. Math Biosci 10: 25-61, 1971.

ATTWELL PJ, COOKE SF, YEO CH: Cerebellar function in consolidation of a motor memory. Neuron 34: 10111020, 2002.

BAST T, ZHANG WN, FELDON J: The ventral hippocampus and fear conditioning in rats. Different anterograde amnesias of fear after tetrodotoxin inactivation and infusion of the GABA(A) agonist muscimol. Exp Brain Res 139: 39-52, 2001.

BERNTSON GG, TORELLO MW: The paleocerebellum and the integration of behavioural function. Physiol Psychol 10: $2-12,1982$.

BERTHIER NE, MOORE JW: Cerebellar Purkinje cell activity related to the classically conditioned nictitating membrane response. Exp Brain Res 63: 341-350, 1986.

BLISS TV, LØMO T: Long-lasting potentiation of synaptic transmission in the dentate area of the anaesthetized rabbit following stimulation of the perforant path. J Physiol 232: 331-356, 1973.

BLITZ DM, REGEHR WG: Timing and specificity of feed-forward inhibition within the LGN. Neuron 45: 917-928, 2005.

CAREW TJ, WALTERS ET, KANDEL ER: Associative learning in Aplysia: cellular correlates supporting a conditioned fear hypothesis. Science 211: 501-504, 1981.

CLUGNET MC, LEDOUX JE: Synaptic plasticity in fear conditioning circuits: induction of LTP in the lateral nucleus of the amygdala by stimulation of the medial geniculate body. $J$ Neurosci 10: 2818-2824, 1990. 
CONQUET F, BASHIR ZI, DAVIES CH, DANIEL H, FERRAGUTI F, BORDI F, FRANZ-BACON K, REGGIANI A, MATARESE V, CONDÉ F, COLLINGRIDGE GL, CRÉPEL F: Motor deficit and impairment of synaptic plasticity in mice lacking mGluR1. Nature 372: 237-243, 1994.

CUDMORE RH, TURRIGIANO GG: Long-term potentiation of intrinsic excitability in LV visual cortical neurons. J Neurophysiol 92: 341-348, 2004.

DAMASIO AR, GRABOWSKI TJ, BECHARA A, DAMASIO H, PONTO LL, PARVIZI J, HICHWA RD: Subcortical and cortical brain activity during the feeling of self-generated emotions. Nat Neurosci 3: 10491056,2000 .

DE ZEEUW CI, SIMPSON JI, HOOGENRAAD CC, GALJART N, KOEKKOEK SK, RUIGROK TJ: Microcircuitry and function of the inferior olive. Trends Neurosci 21: 391-400, 1998.

DOW RS, MORUZZI G: The Physiology and Pathology of the Cerebellum. University of Minnesota Press, Minneapolis, 1958.

ECCLES JC, ITO M, SZENTÀGOTHAI: The Cerebellum as a Neuronal Machine. Springer, Berlin, 1967a.

ECCLES JC, SASAKI K, STRATA P: A comparison of the inhibitory actions of Golgi cells and of basket cells. Exp Brain Res 3: 81-94, 1967b.

FANSELOW MS, KIM JJ, YIPP J, DE OCA B: Differential effects of the N-methyl-D-aspartate antagonist DL-2amino-5-phosphonovalerate on acquisition of fear of auditory and contextual cues. Behav Neurosci 108: 235240, 1994.

FISCHER H, ANDERSSON JL, FURMARK T, FREDRIKSON M: Fear conditioning and brain activity: a positron emission tomography study in humans. Behav Neurosci 114: 671-680, 2000.

FLOURENS P: Recherches Expérimentales sur les Propriétés et les Fonctions du Système Nerveux dans les Animaux Vertébrés. Crevot, Paris, 1824. English translation in CLARKE E, O'MALLEY C: The Human Brain and Spinal Cord, University of California Press, Berkeley and Los Angeles, pp 657-661, 1968.

FUNABIKI K, MISHINA M, HIRANO T: Retarded vestibular compensation in mutant mice deficient in delta 2 glutamate receptor subunit. Neuroreport 7: 189-192, 1995.

GLICKSTEIN M, STRATA P, VOOGD J: Cerebellum: history. Neuroscience 162: 549-559, 2009.

GOOSSENS J, DANIEL H, RANCILLAC A, VAN DER STEEN J, OBERDICK J, CRÉPEL F, DE ZEEUW CI, FRENS MA: Expression of protein kinase $\mathrm{C}$ inhibitor blocks cerebellar long-term depression without affecting Purkinje cell excitability in alert mice. $J$ Neurosci 21: 5813-5823, 2001.

GOULD TJ, STEINMETZ JE: Changes in rabbit cerebellar cortical and interpositus nucleus activity during acquisition, extinction, and backward classical eyelid conditioning. Neurobiol Learn Mem 65: 17-34, 1996.

HIRANO T, KASONO K, ARAKI K, MISHINA M: Suppression of LTD in cultured Purkinje cells deficient in the glutamate receptor delta 2 subunit. Neuroreport 6: 524-526, 1995.

HOLMES G: The symptoms of acute cerebellar injuries due to gunshot injuries. Brain 4: 461-535, 1917.

ITO M: The Cerebellum and Neural Control. Raven Press, New York, 1984.

ITO M: Cerebellar long-term depression: characterization, signal transduction, and functional roles. Physiol Rev 81: 1143-1195, 2001.

IVANOVA SF, BURES J: Conditioned taste aversion is disrupted by prolonged retrograde effects of intracerebral injection of tetrodotoxin in rats. Behav Neurosci 104: 948-954, 1990.

KIM JJ, FANSELOW MS: Modality-specific retrograde amnesia of fear. Science 256: 675-677, 1992.

LANG EJ, PARÉ D: Similar inhibitory processes dominate the responses of cat lateral amygdaloid projection neurons to their various afferents. $J$ Neurophysiol 77: 341-352, 1997.

LEDOUX JE: Emotion, memory and the brain. Sci Am 270: 50-57, 1994.

LEDOUX JE: Emotion circuits in the brain. Annu Rev Neurosci 23: 155-184, 2000.

LEV-RAM V, WONG ST, STORM DR, TSIEN RY: A new form of cerebellar long-term potentiation is postsynaptic and depends on nitric oxide but not cAMP. Proc Natl Acad Sci USA 99: 8389-8393, 2002.

LEVY WB, STEWARD O: Synapses as associative memory elements in the hippocampal formation. Brain Res 175: 233-245, 1979. 
LI XF, ARMONY JL, LEDOUX JE: GABAA and GABAB receptors differentially regulate synaptic transmission in the auditory thalamo-amygdala pathway: an in vivo microiontophoretic study and a model. Synapse 24: 115-124, 1996.

LUCIANI L: Il Cervelletto: Nuovi Studi di Fisiologia Normale e Patologica. Le Monnier, Firenze, 1891.

MARDER E, ABBOTT LF, TURRIGIANO GG, LIU Z, GOLOWASCH J: Memory from the dynamics of intrinsic membrane currents. Proc Natl Acad Sci USA 93: 13481-13486, 1996.

MAREN S: Synaptic transmission and plasticity in the amygdala. An emerging physiology of fear conditioning circuits. Mol Neurobiol 13: 1-22, 1996.

MAREN S: Neurobiology of Pavlovian fear conditioning. Annu Rev Neurosci 24: 897-931, 2001.

MARR D: A theory of cerebellar function. J Physiol 202: 437-470, 1969.

MASCHKE M, SCHUGENS M, KINDSVATER K, DREPPER J, KOLB FP, DIENER HC, DAUM I, TIMMANN D: Fear conditioned changes of heart rate in patients with medial cerebellar lesions. J Neurol Neurosurg Psychiatry 72:116-118, 2002.

MATSUDA S, MIKAWA S, HIRAI H: Phosphorylation of serine-880 in GluR2 by protein kinase C prevents its $\mathrm{C}$ terminus from binding with glutamate receptor-interacting protein. J Neurochem 73: 1765-1768, 1999.

MITTMANN W, KOCH U, HAUSSER M: Feed-forward inhibition shapes the spike output of cerebellar Purkinje cells. J Physiol 563: 369-378, 2005.

MIYATA M, FINCH EA, KHIROUG L, HASHIMOTO K, HAYASAKA S, ODA SI, INOUYE M, TAKAGISHI Y, AUGUSTINE GJ, KANO M: Local calcium release in dendritic spines required for long-term synaptic depression. Neuron 28: 233-244, 2000.

MORUZZI G: Sur les rapports entre le paléocervelet et le réflexes vasomoteurs. Ann Physiol 14: 605-612, 1938.

ODA Y, KAWASAKI K, MORITA M, KORN H, MATSUI H: Inhibitory long-term potentiation underlies auditory conditioning of goldfish escape behaviour. Nature 394: 182-185, 1998.

PLOGHAUS A, TRACEY I, GATI JS, CLARE S, MENON RS, MATTHEWS PM, RAWLINS JN: Dissociating pain from its anticipation in the human brain. Science 284: 1979-1981, 1999.

PLOGHAUS A, TRACEY I, CLARE S, GATI JS, RAWLINS JN, MATTHEWS PM: Learning about pain: the neural substrate of the prediction error for aversive events. Proc Natl Acad Sci USA 97: 9281-9286, 2000.

PLOGHAUS A, BECERRA L, BORRAS C, BORSOOK D: Neural circuitry underlying pain modulation: expectation, hypnosis, placebo. Trends Cogn Sci 7: 197-200, 2003.

POUILLE F, SCANZIANI M: Enforcement of temporal fidelity in pyramidal cells by somatic feed-forward inhibition. Science 293: 1159-1163, 2001.

ROLANDO L: Saggio sopra le vera struttura del cervello dell'uomo e degli animali e sopra le funzioni del sistema nervoso. Sassari: Stamperia da S.S.R.M., 1809.

ROLANDO L: Expériences sur les fonctions du système nerveux. J de Physiol expér 3: 95-113, 1823.

SAAB CY, WILLIS WD: The cerebellum: organization, functions and its role in nociception. Brain Res Brain Res Rev 42: 85-95, 2003.

SAAR D, BARKAI E: Long-term modifications in intrinsic neuronal properties and rule learning in rats. Eur $J$ Neurosci 17: 2727-2734, 2003.

SACCHETTI B, BALDI E, LORENZINI CA, BUCHERELLI C: Cerebellar role in fear-conditioning consolidation. Proc Natl Acad Sci USA 99: 8406-8411, 2002.

SACCHETTI B, SCELFO B, TEMPIA F, STRATA P: Long-term synaptic changes induced in the cerebellar cortex by fear conditioning. Neuron 42: 973-982, 2004.

SACCHETTI B, SCELFO B, STRATA P: The cerebellum: synaptic changes and fear conditioning. Neuroscientist 11: 217-227, 2005.

SACCHETTI B, SCELFO B, STRATA P: Cerebellum and emotional behavior. Neuroscience 162: 756-762, 2009.

SCELFO B, SACCHETTI B, STRATA P: Learning-related long-term potentiation of inhibitory synapses in the cerebellar cortex. Proc Natl Acad Sci USA 105: 769-774, 2008.

SCHMAHMANN JD, SHERMAN JC: The cerebellar cognitive affective syndrome. Brain 121: 561-579, 1998.

SCHMAHMANN JD, MACMORE J, VANGEL M: Cerebellar stroke without motor deficit: clinical evidence for motor and non-motor domains within the human cerebellum. Neuroscience 162: 852-861, 2009. 
SCHREURS BG, ALKON DL: Rabbit cerebellar slice analysis of long-term depression and its role in classical conditioning. Brain Res 631: 235-240, 1993.

SCHREURS BG, TOMSIC D, GUSEV PA, ALKON DL: Dendritic excitability microzones and occluded long-term depression after classical conditioning of the rabbit's nictitating membrane response. $J$ Neurophysiol 77: 86-92, 1997.

SCHREURS BG, GUSEV PA, TOMSIC D, ALKON DL, SHI T: Intracellular correlates of acquisition and long-term memory of classical conditioning in Purkinje cell dendrites in slices of rabbit cerebellar lobule HVI. $J$ Neurosci 18: 5498-5507, 1998.

SINGER T, SEYMOUR B, O'DOHERTY J, KAUBE H, DOLAN RJ, FRITH CD: Empathy for pain involves the affective but not sensory components of pain. Science 303: 1157-1162, 2004.

SNIDER RS: Recent contribution to the anatomy and physiology of the cerebellum. Arch Neurol Psychiatry 64: 196219, 1950.

SNIDER RS, MAITI A: Cerebellar contributions to the Papez circuit. J Neurosci Res 2: 133-146, 1976.

SNIDER RS, STOWELL A: Receiving areas of the tactile auditory and visual systems in the cerebellum. J Neurophysiol 7: 331-358, 1944.

STRATA P: David Marr's theory of cerebellar learning: 40 years later. J Physiol 587: 5519-5520, 2009.

STRICK PL, DUM RP, FIEZ JA: Cerebellum and nonmotor function. Annu Rev Neurosci 32: 413-434, 2009.

SUPPLE WF Jr, LEATON RN, FANSELOW MS: Effects of cerebellar vermal lesions on species-specific fear responses, neophobia, and taste-aversion learning in rats. Physiol Behav 39: 579-586, 1987.

SUPPLE WF, LEATON RN: Lesions of the cerebellar vermis and cerebellar hemispheres: effects on heart rate conditioning in rats. Behav Neurosci 104: 934-947, 1990.

THOMPSON RF: The neurobiology of learning and memory. Science 233: 941-947, 1986.

THOMPSON RF: Neural mechanisms of classical conditioning in mammals. Philos Trans R Soc Lond B Biol Sci 2: 331-337, 1990.

THOMPSON LT, MOYER JR Jr, DISTERHOFT JF: Transient changes in excitability of rabbit CA3 neurons with a time course appropriate to support memory consolidation. J Neurophysiol 76: 1836-1849, 1996.

TURNER BM, PARADISO S, MARVEL CL, PIERSON R, BOLES PONTO LL, HICHWA RD, ROBINSON RG: The cerebellum and emotional experience. Neuropsychologia 45: 1331-1341, 2007.

WILTGEN BJ, SANDERS MJ, FERGUSON C, HOMANICS GE, FANSELOW MS: Trace fear conditioning is enhanced in mice lacking the delta subunit of the GABAA receptor. Learn Mem 12: 327-333, 2005.

ZHU L, SCELFO B, TEMPIA F, SACCHETTI B, STRATA P: Membrane excitability and fear conditioning in cerebellar Purkinje cell. Neuroscience 140: 801-810, 2006.

ZHU L, SCELFO B, HARTELL NA, STRATA P, SACCHETTI B: The effects of fear conditioning on cerebellar LTP and LTD. Eur J Neurosci 26: 219-227, 2007. 